J. Nonlinear Var. Anal. 2 (2018), No. 1, pp. 103-112

Available online at http://jnva.biemdas.com

https://doi.org/10.23952/jnva.2.2018.1.08

\title{
ON REICH'S STRICT FIXED POINT THEOREM FOR MULTI-VALUED OPERATORS IN COMPLETE METRIC SPACES
}

\author{
ADRIAN PETRUŞEL ${ }^{1,2 *}$, GABRIELA PETRUŞEL $^{1}$ \\ ${ }^{1}$ Department of Mathematics and Department of Business, Babeş-Bolyai University, Cluj-Napoca, Romania \\ ${ }^{2}$ Academy of Romanian Scientists, Bucharest, Romania
}

\begin{abstract}
The aim of this paper to present an extended version of Reich' strict fixed point theorem for multi-valued operators. Under the classical assumptions considered by Simeon Reich in 1972 (i.e., the completeness of the metric space $(X, d)$ and the $\delta$-contraction type condition on a self multi-valued operator on $X$ having nonempty and bounded values) several other conclusions with respect to the strict fixed point problem are presented.
\end{abstract}

Keywords. Multi-valued operator; Complete metric space; Fixed point; Ulam-Hyers stability; Well-posedness.

2010 Mathematics Subject Classification. 47H10, 54H25.

\section{INTRODUCTION}

The most important metric fixed point theorem for multi-valued contractions on a complete metric space was given by Nadler [7] and Covitz-Nadler [3]. In the same time, of the major interest is to obtain sufficient conditions for the existence (and uniqueness) of a strict fixed point of a multi-valued operator. In this direction, a very important result was proved by Reich in 1972, see [16]. Several related results and generalizations are known, see, for example, [1] and [5].

The aim of this paper to present an extended (by the conclusions point of view) version of Reich' strict fixed point theorem for multi-valued operators in complete metric spaces. Some related mathematical phenomena will be considered: data dependence, Ulam-Hyers stability, well-posedness, and Ostrovski property. A local fixed point theorem is also proved.

\section{PRELIMINARIES}

Let us recall first some important preliminary concepts and results.

Let $(X, d)$ be a metric space and let $P(X)$ be the family of all nonempty subsets of $X$. We denote by $P_{c l}(X)$ the family of all nonempty closed subsets of $X$ and by $P_{b}(X)$ the family of all nonempty bounded subsets of $X$. Also $P_{b, c l}(X):=P_{b}(X) \cap P_{c l}(X)$. For $x_{0} \in X$ and $r>0$, we will also denote by $B\left(x_{0} ; r\right):=\left\{x \in X \mid d\left(x_{0}, x\right)<r\right\}$ the open ball, respectively by $\tilde{B}\left(x_{0} ; r\right):=\left\{x \in X \mid d\left(x_{0}, x\right) \leq r\right\}$ the closed ball, centered in $x_{0}$ with radius $r$.

${ }^{*}$ Correspondnig author.

E-mail addresses: petrusel@ math.ubbcluj.ro (A. Petruşel), gabi.petrusel@ tbs.ubbcluj.ro (G. Petruşel).

Received December 1, 2017; Accepted January 12, 2018.

(c) 2018 Journal of Nonlinear and Variational Analysis 
We also recall, in the context of a metric space, the definitions of some important functionals in multivalued analysis theory:

(a) the gap functional generated by $d$ :

$$
D_{d}: P(X) \times P(X) \rightarrow \mathbb{R}_{+}, D_{d}(A, B):=\inf \{d(a, b) \mid a \in A, b \in B\} .
$$

(b) the excess functional of $A$ over $B$ generated by $d$ :

$$
e_{d}: P(X) \times P(X) \rightarrow \mathbb{R}_{+} \cup\{+\infty\}, e_{d}(A, B):=\sup \left\{D_{d}(a, B) \mid a \in A\right\} .
$$

(c) the Hausdorff-Pompeiu functional generated by $d$ :

$$
H_{d}: P(X) \times P(X) \rightarrow \mathbb{R}_{+} \cup\{+\infty\}, H_{d}(A, B)=\max \left\{e_{d}(A, B), e_{d}(B, A)\right\} .
$$

(d) the diameter functional generated by $d$ :

$$
\delta_{d}: P(X) \times P(X) \rightarrow \mathbb{R}_{+}, \delta_{d}(A, B):=\sup \{d(a, b) \mid a \in A, b \in B\} .
$$

The diameter of a set $A \in P(X)$ will be denoted by $\operatorname{diam}(A):=\delta_{d}(A, A)$. We will avoid the subscript ${ }_{d}$ if the context is clear.

Some useful properties of these functionals are re-called (see, for example, $[2,6,9]$ ) in the next lemmas.

Lemma 2.1. If $(X, d)$ is a metric space, then we have:

(a) $H$ is a metric in $P_{b, c l}(X)$;

(b) if $A \in P_{c l}(X)$ and $x \in X$ are such that $D(x, A)=0$, then $x \in A$.

(c) if $A, B \in P(X)$ and $q>1$, then, for every $a \in A$ there exists $b \in B$ such that $d(a, b) \leq q H(A, B)$.

(d) if $A, B \in P_{b}(X)$ and $q<1$, then, for every $a \in A$ there exists $b \in B$ such that $d(a, b) \geq q \delta(A, B)$.

(e) the functional $\delta$ has the following properties:

(1) $\delta(A, B)=0$ implies that $A=B=\left\{x^{*}\right\}$;

(2) $\delta(A, B) \leq \delta(A, C)+\delta(C, B)$, for all $A, B, C \in P_{b}(X)$;

(3) $\delta(A, B)=\delta(B, A)$, for all $A, B \in P_{b}(X)$;

(4) if $A \in P_{b}(X)$ then $\delta(A, A)=0$ if and only if $A$ is a singleton.

Finally, let us recall that if $X$ is a nonempty set and $F: X \rightarrow P(X)$ is a multi-valued operator, then we denote by $F i x(F):=\{x \in X: x \in F(x)\}$ the fixed point set for $F$, and by $\operatorname{SFix}(F):=\{x \in X:\{x\}=F(x)\}$ the strict fixed point set for $F$. In some papers, instead of strict fixed point the terms stationary point or end-point are used. We also denote by $\operatorname{Graph}(F):=\{(x, y) \in X \times X \mid y \in F(x)\}$ the graph of $F$.

Moreover, for arbitrary $\left(x_{0}, x_{1}\right) \in \operatorname{Graph}(F)$, the sequence $\left(x_{n}\right)_{n \in \mathbb{N}}$ with $x_{n+1} \in F\left(x_{n}\right)$ (for $n \in\{1,2,3, \cdots\}$ ) is called the sequence of successive approximations for $F$ staring from $\left(x_{0}, x_{1}\right)$.

Some typical conditions in fixed point theory for a multi-valued operator are given now.

Definition 2.1. Let $(X, d)$ be a metric space. Then:

1) $F: X \rightarrow P_{c l}(X)$ is called $(\alpha, \beta)$-contraction of Reich type if $\alpha, \beta \geq 0, \alpha+2 \beta<1$ and

$$
H\left(F\left(x_{1}\right), F\left(x_{2}\right)\right) \leq \alpha d\left(x_{1}, x_{2}\right)+\beta\left(D_{d}\left(x_{1}, F\left(x_{1}\right)\right)+D_{d}\left(x_{2}, F\left(x_{2}\right)\right)\right), \quad \forall x_{1}, x_{2} \in X .
$$

We notice that in [4] the case when $\alpha=0$ is treated. This kind of mappings are called Kannan type multi-valued operators. 
2) $F: X \rightarrow P_{b}(X)$ is called $(\alpha, \beta)-\delta$-contraction of Reich type if $\alpha, \beta \geq 0, \alpha+2 \beta<1$ and

$$
\delta\left(F\left(x_{1}\right), F\left(x_{2}\right)\right) \leq \alpha d\left(x_{1}, x_{2}\right)+\beta\left(\delta_{d}\left(x_{1}, F\left(x_{1}\right)\right)+\delta_{d}\left(x_{2}, F\left(x_{2}\right)\right)\right), \quad \forall x_{1}, x_{2} \in X ;
$$

The concepts of multi-valued weakly Picard operator and multi-valued Picard operator are very important in fixed point theory for multi-valued operators.

Definition 2.2. ([11, 20,21]) Let $(X, d)$ be a metric space. Then $F: X \rightarrow P(X)$ is called a multivalued weakly Picard operator (briefly, MWP operator) if for each $x \in X$ and each $y \in F(x)$ there exists a sequence $\left\{x_{n}\right\}_{n \in \mathbb{N}}$ in $X$ such that

(i) $x_{0}=x, x_{1}=y$;

(ii) $x_{n+1} \in F\left(x_{n}\right)$, for all $n \in \mathbb{N}$;

(iii) the sequence $\left\{x_{n}\right\}_{n \in \mathbb{N}}$ is convergent and its limit is a fixed point of $F$.

Let us recall the following important notion.

Definition 2.3. Let $(X, d)$ be a metric space and let $F: X \rightarrow P(X)$ be an MWP operator. Then we define the multivalued operator $F^{\infty}: \operatorname{Graph}(F) \rightarrow P(F i x(F))$ by the formula $F^{\infty}(x, y)=\{z \in F i x(F) \mid$ there exists a sequence of successive approximations of $F$ starting from $(x, y)$ that converges to $z\}$.

An important concept is given by the following definition.

Definition 2.4. Let $(X, d)$ be a metric space and $F: X \rightarrow P(X)$ an MWP operator. Then $F$ is a $\psi$-multivalued weakly Picard operator (briefly $\psi$-MWP operator) if $\psi: \mathbb{R}_{+} \rightarrow \mathbb{R}_{+}$is increasing, continuous in 0 with $\psi(0)=0$ and there exists a selection $f^{\infty}$ of $F^{\infty}$ such that

$$
d\left(x, f^{\infty}(x, y)\right) \leq \psi(d(x, y)), \text { for all }(x, y) \in \operatorname{Graph}(F) .
$$

In particular, if $\psi(t)=c t$, we say that $F$ is a $c$-multi-valued weakly Picard operator (briefly $c$-MWP operator).

Example 2.1. An $(\alpha, \beta)$-contraction of Reich type is a $c$-MWP operator with $c:=\frac{1-\beta}{1-(\alpha+\beta)}$.

Definition 2.5. ([11, 12]) We say that $F: X \rightarrow P(X)$ is a multi-valued Picard operator if:

(i) $\operatorname{SFix}(F)=\operatorname{Fix}(F)=\left\{x^{*}\right\}$;

(ii) $F^{n}(x) \stackrel{H_{d}}{\rightarrow}\left\{x^{*}\right\}$ as $n \rightarrow \infty$, for each $x \in X$.

Several examples of Picard and weakly Picard operators, as well as, different applications of this theory are given, for example, in $[9,10,11,12,14]$.

\section{REICH'S STRICT FIXED POINT THEOREM}

In this section, the study of the fixed point problem for $(\alpha, \beta)-\delta$-contractions of Reich type is considered.

In 1972, Reich proved the following strict fixed point principle (see [19] for other similar results).

Theorem 3.1. (Reich's Theorem) Let $(X, d)$ be a complete metric space and $F: X \rightarrow P_{b}(X)$ be a multivalued operator for which there exist $\alpha, \beta \in \mathbb{R}_{+}$with $0<\alpha+2 \beta<1$ such that

$$
\delta(F(x), F(y)) \leq \alpha d(x, y)+\beta(\delta(x, F(x))+\delta(y, F(y))), \quad \forall x, y \in X .
$$

Then there exists a unique strict fixed point $x^{*} \in X$ of $F$ and $F i x(F)=\operatorname{SFix}(F)=\left\{x^{*}\right\}$. 
Proof. A. Reich's original proof. Let $p:=\sqrt{\alpha+2 \beta} \in(0,1)$. Then, by Lemma 2.1, we can define a selection $f: X \rightarrow X$ of $F$, by letting to each point $x \in X$ the point $f(x) \in F(x)$ which satisfies $d(x, f(x)) \geq$ $p \delta(x, F(x))$. Then, we have

$$
\begin{aligned}
d(f(x), f(y)) & \leq \delta(F(x), F(y)) \\
& \leq \alpha d(x, y)+\beta(\delta(x, F(x))+\delta(y, F(y))) \\
& \leq \alpha d(x, y)+\beta p^{-1}(d(x, f(x))+d(y, f(y))) .
\end{aligned}
$$

Since $\alpha+2 \beta p^{-1}<p^{-1}(\alpha+2 \beta)=p<1$, we obtain that $f$ satisfies all the conditions of Círić-Reich-Rus' Theorem (see [15], [17]) and hence it has a unique fixed point $x^{*} \in X$. Thus, $x^{*} \in F i x(F)$. Moreover, since $0=d\left(x^{*}, f\left(x^{*}\right)\right) \geq p \delta\left(x^{*}, F\left(x^{*}\right)\right)$, we get $\delta\left(x^{*}, F\left(x^{*}\right)\right)=0$ and so $F\left(x^{*}\right)=\left\{x^{*}\right\}$. Hence, $x^{*} \in \operatorname{SFix}(F)$. We show now that $F i x(F) \subset \operatorname{SFix}(F)$. Indeed, let $y \in F i x(F)$. If we If we suppose that $\delta(y, F(y))>0$, then

$$
\delta(F(y), F(y)) \leq 2 \beta \delta(y, F(y)) \leq \delta(y, F(y)),
$$

which is a contradiction. Thus $F(y)=\{y\}$, i.e., $y \in \operatorname{SFix}(F)$. For the uniqueness of the fixed point (and the strict fixed point too), we notice that, if $z \in X$ is another strict fixed point of $F$ such that $x^{*} \neq z$, then we have

$$
\begin{aligned}
d\left(x^{*}, z\right) & \leq \delta\left(F\left(x^{*}\right), F(z)\right) \\
& \leq \alpha d\left(x^{*}, z\right)+\beta\left(\delta\left(x^{*}, F\left(x^{*}\right)\right)+\delta(z, F(z))\right) \\
& =\alpha d\left(x^{*}, z\right) .
\end{aligned}
$$

Thus $z=x^{*}$.

$B$. An alternative proof. Let $q>1$ and let $x_{0} \in X$ be arbitrary. Then there exists $x_{1} \in F\left(x_{0}\right)$ such that $\delta\left(x_{0}, F\left(x_{0}\right)\right) \leq q \cdot d\left(x_{0}, x_{1}\right)$. Thus, we have

$$
\begin{aligned}
\delta\left(x_{1}, F\left(x_{1}\right)\right) & \leq \delta\left(F\left(x_{0}\right), F\left(x_{1}\right)\right) \\
& \leq \alpha d\left(x_{0}, x_{1}\right)+\beta\left(\delta\left(x_{0}, F\left(x_{0}\right)\right)+\delta\left(x_{1}, F\left(x_{1}\right)\right)\right) \\
& \leq \alpha d\left(x_{0}, x_{1}\right)+\beta q d\left(x_{0}, x_{1}\right)+\beta \delta\left(x_{1}, F\left(x_{1}\right)\right) .
\end{aligned}
$$

Hence, we get $\delta\left(x_{1}, F\left(x_{1}\right)\right) \leq \frac{\alpha+\beta q}{1-\beta} d\left(x_{0}, x_{1}\right)$. By this approach we can construct a sequence $\left(x_{n}\right)_{n \in \mathbb{N}} \subset X$ of successive approximations for $F$, such that

$$
d\left(x_{n}, x_{n+1}\right) \leq \delta\left(x_{n}, F\left(x_{n}\right)\right) \leq\left(\frac{\alpha+\beta q}{1-\beta}\right)^{n} d\left(x_{0}, x_{1}\right), \quad \forall n \in \mathbb{N} .
$$

Choosing $q<\frac{1-\alpha-\beta}{\beta}$ we obtain $\frac{\alpha+\beta q}{1-\beta}<1$. Hence $\left(x_{n}\right)_{n \in \mathbb{N}}$ ia a Cauchy sequence in the complete metric space $(X, d)$. Let us denote by $x^{*} \in X$ its limit. We show that $x^{*}$ is a strict fixed point for $F$, i.e., $F\left(x^{*}\right)=\left\{x^{*}\right\}$. Indeed, since

$$
\begin{aligned}
\delta\left(x^{*}, F\left(x^{*}\right)\right) & \leq d\left(x^{*}, x_{n+1}\right)+D\left(x_{n+1}, F\left(x_{n}\right)\right)+\delta\left(F\left(x_{n}\right), F\left(x^{*}\right)\right) \\
& \leq d\left(x^{*}, x_{n+1}\right)+\alpha d\left(x_{n}, x^{*}\right)+\beta \delta\left(x_{n}, F\left(x_{n}\right)\right)+\beta \delta\left(x^{*}, F\left(x^{*}\right)\right) \\
& \leq d\left(x^{*}, x_{n+1}\right)+\alpha d\left(x_{n}, x^{*}\right)+\beta\left(\frac{\alpha+\beta q}{1-\beta}\right)^{n} \cdot d\left(x_{0}, x_{1}\right)+\beta \delta\left(x^{*}, F\left(x^{*}\right)\right),
\end{aligned}
$$

we obtain that

$$
\delta\left(x^{*}, F\left(x^{*}\right)\right) \leq \frac{1}{1-\beta}\left(d\left(x^{*}, x_{n+1}\right)+\alpha d\left(x_{n}, x^{*}\right)+\beta\left(\frac{\alpha+\beta q}{1-\beta}\right)^{n} \cdot d\left(x_{0}, x_{1}\right)\right) .
$$


As $n \rightarrow \infty$, we obtain that $\delta\left(x^{*}, F\left(x^{*}\right)\right)=0$ and thus $F\left(x^{*}\right)=\left\{x^{*}\right\}$. The fact that $F i x(F)=\operatorname{SFix}(F)$ and the uniqueness of the strict fixed point follow as before.

Remark 3.1. 1) In fact, in [16], the following assumption is made: there exist $\alpha, \beta, \gamma \in \mathbb{R}_{+}$with $\alpha+$ $\beta+\gamma<1$ such that

$$
\delta(F(x), F(y)) \leq \alpha d(x, y)+\beta \delta(x, F(x))+\gamma \delta(y, F(y)), \quad \forall x, y \in X
$$

2) By the alternative proof, it also follows that there exists a sequence $\left(x_{n}\right)_{n \in \mathbb{N}}$ of successive approximations for $F$ starting from arbitrary $x_{0} \in X$, such that

$$
d\left(x_{n}, x^{*}\right) \leq \frac{L^{n}}{1-L} d\left(x_{0}, x_{1}\right), \quad \forall n \in \mathbb{N},
$$

where $L=\frac{\alpha+\beta q}{1-\beta}$, with any $q \in\left(1, \frac{1-\alpha-\beta}{\beta}\right)$.

On the other hand, it is worth to notice that by Reich's original proof we also obtain, taking into account the proof of Círić-Reich-Rus' Theorem (see [15], [17]), that the sequence $u_{n}=f^{n}\left(x_{0}\right)$, for $n \in \mathbb{N}^{*}$ (where $x_{0}$ is arbitrary in $X$ ) converges to $x^{*} \in F i x(f)$ and the following apriori estimation holds

$$
d\left(u_{n}, x^{*}\right) \leq \frac{s^{n}}{1-s} d\left(x_{0}, f\left(x_{0}\right)\right), \quad \forall n \in \mathbb{N},
$$

where $s=\frac{\alpha+\beta}{1-\beta}<1$. Hence, for the strict fixed point $x^{*} \in X$ the following estimation holds

$$
d\left(u_{n}, x^{*}\right) \leq \frac{s^{n}}{1-s} d\left(x_{0}, x_{1}\right), \quad \forall n \in \mathbb{N},
$$

where $u_{n}=f^{n}\left(x_{0}\right) \rightarrow x^{*}$ as $n \in \mathbb{N}^{*}$ (where $x_{0}$ is arbitrary in $X$ and $f: X \rightarrow X$ is the selection constructed in Reich's original proof).

3) It is worth to notice that the following Kannan type assumption

$$
H(F(x), F(y)) \leq \beta(\delta(x, F(x))+\delta(y, F(y))), \quad \forall x, y \in X,
$$

(where $\beta \in\left(0, \frac{1}{2}\right)$ ) does not imply, in general, the existence of a fixed point (see [16] Example 1). Moreover, if we impose the assumption

$$
H(F(x), F(y)) \leq \alpha d(x, y)+\beta(\delta(x, F(x))+\delta(y, F(y))), \quad \forall x, y \in X,
$$

(where $\alpha+2 \beta<1$ ) the existence of a fixed point for $F$ was established just for the case when $X:=\mathbb{R}$, see [16] Proposition 1.

In fact, the above remarks lead to some interesting open questions.

Moreover, we can prove the following interesting result, see also [10].

Theorem 3.2. Let $(X, d)$ be a complete metric space and $F: X \rightarrow P_{b}(X)$ be a multi-valued operator for which there exist $\alpha, \beta \in \mathbb{R}_{+}$with $0<\alpha+2 \beta<1$, such that

$$
\delta(F(x), F(y)) \leq \alpha d(x, y)+\beta(\delta(x, F(x))+\delta(y, F(y))), \quad \forall x, y \in X .
$$

Then $F$ is a MP operator. 
Proof. By Theorem 3.1 we know that $\operatorname{Fix}(F)=\operatorname{SFix}(F)=\left\{x^{*}\right\}$. We have to prove that $F^{n}(x) \stackrel{H_{d}}{\rightarrow}\left\{x^{*}\right\}$ as $n \rightarrow \infty$, for each $x \in X$. We have, for every $x \in X$, that

$$
\begin{aligned}
\delta\left(F(x), x^{*}\right) & =\delta\left(F(x), F\left(x^{*}\right)\right) \\
& \leq \alpha d\left(x, x^{*}\right)+\beta\left(\delta(x, F(x))+\delta\left(x^{*}, F\left(x^{*}\right)\right)\right) \\
& =\alpha d\left(x, x^{*}\right)+\beta \delta(x, F(x)) \\
& \leq \alpha d\left(x, x^{*}\right)+\beta\left(d\left(x, x^{*}\right)+\delta\left(x^{*}, F(x)\right)\right) .
\end{aligned}
$$

Thus

$$
\delta\left(F(x), x^{*}\right) \leq \frac{\alpha+\beta}{1-\beta} d\left(x, x^{*}\right), \quad \forall x \in X
$$

It follows that

$$
\delta\left(F^{2}(x), x^{*}\right)=\sup _{y \in F(x)} \delta\left(F(y), x^{*}\right) \leq \sup _{y \in F(x)}\left(\frac{\alpha+\beta}{1-\beta}\right) d\left(y, x^{*}\right) \leq\left(\frac{\alpha+\beta}{1-\beta}\right)^{2} d\left(x, x^{*}\right) .
$$

By mathematical induction, we get that

$$
\delta\left(F^{n}(x), x^{*}\right) \leq\left(\frac{\alpha+\beta}{1-\beta}\right)^{n} d\left(x, x^{*}\right) \rightarrow 0 \text { as } n \rightarrow+\infty, \text { for each } x \in X .
$$

The proof is now complete.

In some situations, it is important to get a localization of the (strict) fixed point for a multi-valued operator. In the case of $(\alpha, \beta)-\delta$-contractions of Reich type we have the following local fixed point theorem.

Theorem 3.3. Let $(X, d)$ be a complete metric space, $x_{0} \in X$ and $r>0$. Suppose that $F: \tilde{B}\left(x_{0} ; r\right) \rightarrow P_{b}(X)$ is a multi-valued operator for which:

(a) there exist $\alpha, \beta \in \mathbb{R}_{+}$with $0<\alpha+2 \beta<1$ such that

$$
\delta(F(x), F(y)) \leq \alpha d(x, y)+\beta(\delta(x, F(x))+\delta(y, F(y))), \quad \forall \tilde{B}\left(x_{0} ; r\right) \in X ;
$$

(b) $\delta\left(x_{0}, F\left(x_{0}\right)\right) \leq \frac{1-\alpha-2 \beta}{1+\beta} r$.

Then there exists a unique $x^{*} \in \tilde{B}\left(x_{0} ; r\right)$ such that $\operatorname{SFix}(F)=F i x(F)=\left\{x^{*}\right\}$. In particular, if $\beta>0$, then $x^{*} \in B\left(x_{0} ; r\right)$.

Proof. We will show that the closed ball $\tilde{B}\left(x_{0} ; r\right)$ is invariant with respect to $F$, i.e., $F\left(\tilde{B}\left(x_{0} ; r\right)\right) \subseteq \tilde{B}\left(x_{0} ; r\right)$. For this purpose, let $x \in \tilde{B}\left(x_{0} ; r\right)$ and $y \in F(x)$ be arbitrary chosen. Then we have

$$
d\left(y, x_{0}\right) \leq \delta\left(F(x), F\left(x_{0}\right)\right)+\delta\left(x_{0}, F\left(x_{0}\right)\right) .
$$

On the other hand,

$$
\begin{aligned}
\delta\left(F(x), F\left(x_{0}\right)\right) & \leq \alpha r+\beta\left(\delta(x, F(x))+\delta\left(x_{0}, F\left(x_{0}\right)\right)\right) \\
& \leq \alpha r+\beta\left(d\left(x, x_{0}\right)+\delta\left(x_{0}, F\left(x_{0}\right)\right)+\delta\left(F\left(x_{0}\right), F(x)\right)+\delta\left(x_{0}, F\left(x_{0}\right)\right)\right) \\
& =(\alpha+\beta) r+2 \beta \delta\left(x_{0}, F\left(x_{0}\right)\right)+\beta \delta\left(F\left(x_{0}\right), F(x)\right) .
\end{aligned}
$$

Hence

$$
\delta\left(F(x), F\left(x_{0}\right)\right) \leq \frac{(\alpha+\beta) r+2 \beta \delta\left(x_{0}, F\left(x_{0}\right)\right)}{1-\beta}
$$


Hence, going back to our first relation, we get

$$
\begin{aligned}
d\left(y, x_{0}\right) & \leq \frac{(\alpha+\beta) r+\beta \delta\left(x_{0}, F\left(x_{0}\right)\right)}{1-\beta}+\delta\left(x_{0}, F\left(x_{0}\right)\right) \\
& =\frac{(\alpha+\beta) r+(\beta+1) \delta\left(x_{0}, F\left(x_{0}\right)\right)}{1-\beta} .
\end{aligned}
$$

By (b) we obtain that $d\left(y, x_{0}\right) \leq r$, proving that the closed ball $\tilde{B}\left(x_{0} ; r\right)$ is invariant with respect to $F$. The conclusion follows now by Theorem 3.1.

If $\beta>0$, then we can show that $x^{*} \in B\left(x_{0} ; r\right)$. Indeed, suppose, by contradiction, that $d\left(x^{*}, x_{0}\right)=r$. Then we have

$$
\begin{aligned}
r & =d\left(x^{*}, x_{0}\right) \\
& \leq \delta\left(F\left(x^{*}\right), F\left(x_{0}\right)\right)+\delta\left(x_{0}, F\left(x_{0}\right)\right) \\
& \leq \alpha d\left(x^{*}, x_{0}\right)+(\beta+1) \delta\left(x_{0}, F\left(x_{0}\right)\right) \\
& \leq \alpha r+(\beta+1) \frac{1-\alpha-2 \beta}{1+\beta} r=(1-2 \beta) r,
\end{aligned}
$$

which gives the necessary contradiction. The proof is now complete.

We will discuss now the well-posedness of the strict fixed point problem. For the well-posedness concept in the single-valued case see the paper Reich-Zaslavski [18], while the multi-valued case is considered in [13].

Definition 3.1. Let $(X, d)$ be a metric space and $F: X \rightarrow P_{b}(X)$ be a multivalued operator. The strict fixed point problem

$$
\{x\}=F(x), x \in X
$$

is well-posed for $F$ if:

$\left(a_{2}\right) \operatorname{SFix}(F)=\left\{x^{*}\right\}$

$\left(b_{2}\right)$ If $\left(x_{n}\right)_{n \in \mathbb{N}}$ is a sequence in $X$ such that $\delta_{d}\left(x_{n}, F\left(x_{n}\right)\right) \rightarrow 0$ as $n \rightarrow+\infty$, then $x_{n} \rightarrow x^{*}$ as $n \rightarrow+\infty$.

In this respect, we have the following result.

Theorem 3.4. Let $(X, d)$ be a complete metric space and $F: X \rightarrow P_{b}(X)$ be a multi-valued operator for which there exist $\alpha, \beta \in \mathbb{R}_{+}$with $0<\alpha+2 \beta<1$ such that

$$
\delta(F(x), F(y)) \leq \alpha d(x, y)+\beta(\delta(x, F(x))+\delta(y, F(y))), \quad \forall x, y \in X .
$$

Then the strict fixed point problem is well-posed for $F$.

Proof. By Theorem 3.1 we know that $\operatorname{Fix}(F)=\operatorname{SFix}(F)=\left\{x^{*}\right\}$. Let $\left(x_{n}\right)_{n \in \mathbb{N}}$ be a sequence in $X$ such that $\delta_{d}\left(x_{n}, F\left(x_{n}\right)\right) \rightarrow 0$ as $n \rightarrow+\infty$. We will prove that $x_{n} \rightarrow x^{*}$ as $n \rightarrow+\infty$. For this purpose, we have

$$
\begin{aligned}
d\left(x_{n}, x^{*}\right) & \leq \delta\left(x_{n}, F\left(x_{n}\right)\right)+\delta\left(F\left(x_{n}\right), F\left(x^{*}\right)\right) \\
& \leq \delta\left(x_{n}, F\left(x_{n}\right)\right)+\alpha d\left(x_{n}, x^{*}\right)+\beta\left(\delta\left(x_{n}, F\left(x_{n}\right)\right)+\delta\left(x^{*}, F\left(x^{*}\right)\right)\right) \\
& =(1+\beta) \delta\left(x_{n}, F\left(x_{n}\right)\right)+\alpha d\left(x_{n}, x^{*}\right) .
\end{aligned}
$$

Letting $n \rightarrow \infty$, we obtain the desired conclusion.

We will continue our study by presenting the concept of Ulam-Hyers stability for the strict fixed point problem. For related definitions and results, see [8]. 
Definition 3.2. Let $(X, d)$ be a metric space and $F: X \rightarrow P_{b}(X)$ be a multi-valued operator. The strict fixed point problem (3.1) is called Ulam-Hyers stable if there exists $c>0$ such that for each $\varepsilon>0$ and for each $\varepsilon$-solution $y \in X$ of the strict fixed point problem, i.e.,

$$
\delta(y, F(y)) \leq \varepsilon,
$$

there exists a solution $x^{*} \in X$ of the strict fixed point inclusion (3.1) such that

$$
d\left(y, x^{*}\right) \leq c \varepsilon .
$$

We have the following result concerning the Ulam-Hyers stability of the strict fixed point problem.

Theorem 3.5. Let $(X, d)$ be a complete metric space and $F: X \rightarrow P_{b}(X)$ be a multi-valued operator for which there exist $\alpha, \beta \in \mathbb{R}_{+}$with $0<\alpha+2 \beta<1$ such that

$$
\delta(F(x), F(y)) \leq \alpha d(x, y)+\beta(\delta(x, F(x))+\delta(y, F(y))), \quad \forall x, y \in X .
$$

Then the strict fixed point problem is Ulam-Hyers stable.

Proof. By Theorem 3.1, we know that $\operatorname{Fix}(F)=\operatorname{SFix}(F)=\left\{x^{*}\right\}$. Let $\varepsilon>0$ and $y \in X$ such that $\delta(y, F(y)) \leq \varepsilon$. Then, we have

$$
\begin{aligned}
d\left(y, x^{*}\right) & \leq \delta(y, F(y))+\delta\left(F(y), F\left(x^{*}\right)\right) \\
& \leq \delta(y, F(y))+\alpha d\left(y, x^{*}\right)+\beta\left(\delta(y, F(y))+\delta\left(x^{*}, F\left(x^{*}\right)\right)\right) \\
& =(1+\beta) \delta(y, F(y))+\alpha d\left(y, x^{*}\right) .
\end{aligned}
$$

Thus

$$
d\left(y, x^{*}\right) \leq \frac{1+\beta}{1-\alpha} \delta(y, F(y)) \leq \frac{1+\beta}{1-\alpha} \varepsilon
$$

The proof is complete.

Another stability concept is given in the next definition.

Definition 3.3. Let $(X, d)$ be a metric space and $F: X \rightarrow P(X)$ be a multi-valued operator with SFix $(F)=$ $\left\{x^{*}\right\}$. If $\left(y_{n}\right)_{n \in \mathbb{N}}$ is a sequence in $X$ such that the following implication holds

$$
D\left(y_{n+1}, F\left(y_{n}\right)\right) \rightarrow 0 \text { as } n \rightarrow \infty \Rightarrow y_{n} \rightarrow x^{*} \text { as } n \rightarrow \infty,
$$

then we say that the strict fixed point problem (3.1) has the Ostrovski property.

Theorem 3.6. Let $(X, d)$ be a complete metric space and $F: X \rightarrow P_{b}(X)$ be a multi-valued operator for which there exist $\alpha, \beta \in \mathbb{R}_{+}$with $0<\alpha+2 \beta<1$ such that

$$
\delta(F(x), F(y)) \leq \alpha d(x, y)+\beta(\delta(x, F(x))+\delta(y, F(y))), \quad \forall x, y \in X .
$$

Then the strict fixed point problem as the Ostrovski property.

Proof. By Theorem 3.1, we know that $\operatorname{Fix}(F)=\operatorname{SFix}(F)=\left\{x^{*}\right\}$. Let $\left(y_{n}\right)_{n \in \mathbb{N}}$ be a sequence in $X$ such that $D\left(y_{n+1}, F\left(y_{n}\right)\right) \rightarrow 0$ as $n \rightarrow \infty$. Next, we have

$$
d\left(y_{n+1}, x^{*}\right) \leq D\left(y_{n+1}, F\left(y_{n}\right)\right)+\delta\left(F\left(y_{n}\right), x^{*}\right) .
$$


On the other hand, we observe that

$$
\begin{aligned}
\delta\left(F\left(y_{n}\right), x^{*}\right) & =\delta\left(F\left(y_{n}\right), F\left(x^{*}\right)\right) \leq \alpha d\left(y_{n}, x^{*}\right)+\beta \delta\left(y_{n}, F\left(y_{n}\right)\right) \\
& \leq \alpha d\left(y_{n}, x^{*}\right)+\beta\left(d\left(y_{n}, x^{*}\right)+\delta\left(x^{*}, F\left(y_{n}\right)\right)\right) \\
& =(\alpha+\beta) d\left(y_{n}, x^{*}\right)+\beta \delta\left(x^{*}, F\left(y_{n}\right)\right) .
\end{aligned}
$$

Hence

$$
\delta\left(F\left(y_{n}\right), x^{*}\right) \leq \frac{\alpha+\beta}{1-\beta} d\left(y_{n}, x^{*}\right), \quad \forall n \in \mathbb{N} .
$$

Denote $p:=\frac{\alpha+\beta}{1-\beta} \in(0,1)$. As a consequence, we obtain

$$
\begin{aligned}
d\left(y_{n+1}, x^{*}\right) & \leq D\left(y_{n+1}, F\left(y_{n}\right)\right)+p d\left(y_{n}, x^{*}\right) \\
& \leq \cdots \\
& \leq \sum_{k=0}^{n} p^{k} D\left(y_{n-k+1}, F\left(y_{n-k}\right)\right)+p^{n+1} d\left(y_{0}, x^{*}\right) .
\end{aligned}
$$

By Cauchy's Lemma (see [14]), we obtain the desired conclusion.

Finally, we will present a data dependence theorem for the strict fixed point problem.

Theorem 3.7. Let $(X, d)$ be a complete metric space and $F: X \rightarrow P_{b}(X)$ be a multi-valued operator for which there exist $\alpha, \beta \in \mathbb{R}_{+}$with $0<\alpha+2 \beta<1$ such that

$$
\delta(F(x), F(y)) \leq \alpha d(x, y)+\beta(\delta(x, F(x))+\delta(y, F(y))), \quad \forall x, y \in X .
$$

Suppose that $G: X \rightarrow P_{b}(X)$ is a multi-valued operator such that SFix $(G) \neq \emptyset$ and there exists $\eta>0$ such that $\delta(F(x), G(x)) \leq \eta$, for every $x \in X$. Then

$$
\delta(\operatorname{SFix}(F), \operatorname{SFix}(G)) \leq \frac{\eta}{1-\alpha} .
$$

Proof. By Theorem 3.1, we know that $\operatorname{Fix}(F)=\operatorname{SFix}(F)=\left\{x^{*}\right\}$. Let $y \in \operatorname{SFix}(G)$ be arbitrary chosen. Then, we also have

$$
\begin{aligned}
d\left(y, x^{*}\right) & =\delta\left(G(y), F\left(x^{*}\right)\right) \\
& \leq \delta(G(y), F(y))+\delta\left(F(y), F\left(x^{*}\right)\right) \\
& \leq \eta+\alpha d\left(y, x^{*}\right) .
\end{aligned}
$$

Thus $d\left(y, x^{*}\right) \leq \frac{\eta}{1-\alpha}$, which gives immediately the desired conclusion.

\section{Acknowledgment}

The author is grateful to the reviewers for useful suggestions which improved the contents of this paper.

\section{REFERENCES}

[1] O. Acar, I. Altun, A fixed point theorem for multivalued mappings with $\delta$-distance, Abst. Appl. Anal. 2014 (2014), Article ID 497092.

[2] G. Beer, Topologies on Closed and Closed Convex Sets, Kluwer Academic Publishers, Dordrecht, 1993.

[3] H. Covitz, S.B. Nadler, Multi-valued contraction mappings in generalized metric spaces, Israel J. Math. 8 (1970), 5-11.

[4] L.S. Dube, S.P. Singh,On multivalued contraction mapping, Bull. Math. Soc. Set. Math. R. S. Roumanie 14 (1970), 307310. 
[5] K. Iseki, Multi-valued contractions mappings in complete metric spaces, Rendiconti Sem. Mat. Univ. Padova, 53 (1975), 15-19.

[6] S. Hu, N.S. Papageorgiou, Handbook of Multivalued Analysis, Volume I: Theory, Kluwer Academic Publishers, Dordrecht, 1997.

[7] S.B. Nadler Jr., Multi-valued contraction mappings, Pacific J. Math. 30 (1969), 475-488.

[8] P.T. Petru, A. Petruşel, J.-C. Yao, Ulam-Hyers stability for operatorial equations and inclusions via nonself operators, Taiwanese J. Math., 15 (2011), 2195-2212.

[9] A. Petruşel, Multi-valued weakly Picard operators and applications, Sci. Math. Japan. 59 (2004), 169-202.

[10] A. Petruşel, G. Petruşel, Multivalued Picard operators, J. Nonlinear Convex Anal. 13 (2012), 157-171.

[11] A. Petruşel, I.A. Rus, Multivalued Picard and weakly Picard operators, Fixed Point Theory and Applications, Yokohama Publishers, pp. 207-226, 2004.

[12] A. Petruşel, I.A. Rus, The theory of a metric fixed point theorem for multivalued operators, In Proc Ninth International Conference on Fixed Point Theory and its Applications, Changhua, Taiwan, July 16-22 (2009), Yokohama Publishers, pp. $161-175,2010$.

[13] A. Petrussel, I.A. Rus, J.-C. Yao, Well-posedness in the generalized sense of the fixed point problems, Taiwanese J. Math. 11 (2007), 903-914.

[14] A. Petruşel, I.A. Rus, M.A. Şerban, Basic problems of the metric fixed point theory and the relevance of a metric fixed point theorem for multivalued operators, J. Nonlinear Convex Anal. 15 (2014), 493-513.

[15] S. Reich, Some remarks concerning contractions mappings, Canad. Math. Bull., 14 (1971), 121-124.

[16] S. Reich, Fixed point of contractive functions, Boll. Un. Mat. Ital. 5 (1972), 26-42.

[17] S. Reich, Kannan's fixed point theorem, Boll. Un. Mat. Ital. 4 (1971), 1-11.

[18] S. Reich, A.J. Zaslavski, Well-posedness of fixed point problems, Far East J. Math. Sci. Special Volume: Functional Analysis and Its Applications, Part III, 393-401, 2001.

[19] I.A. Rus, Generalized Contractions and Applications, Cluj University Press, 2001.

[20] I.A. Rus, A. Petruşel, G. Petruşel, Fixed Point Theory, Cluj University Press, 2008.

[21] I.A. Rus, A. Petruşel and A. Sîntămărian, Data dependence of the fixed point set of some multivalued weakly Picard operators, Nonlinear Anal. 52 (2003), 1947-1959. 